\title{
Correction to: The Possibility of Both Low Friction and Low Leakage by Surface Texture of Mechanical Seals in Blood
}

\author{
Koki Kanda ${ }^{1} \cdot$ Shigeru Tazawa ${ }^{2} \cdot$ Tsuyoshi Urano $^{2} \cdot$ Shinji Kobayashi $^{2} \cdot$ Koshi Adachi $^{1}$
}

Published online: 20 May 2020

๑) Springer Science+Business Media, LLC, part of Springer Nature 2020

Correction to: Tribology Letters (2020) 68:65 https://doi.org/10.1007/s11249-020-01289-7

The original version of this article unfortunately contain mistakes.

1. The affiliation information was incorrect for the coauthors Shigeru Tazawa, Tsuyoshi Urano, Shinji Kobayashi.

The correct affiliation is given below.

Shigeru Tazawa, Tsuyoshi Urano, Shinji Kobayashi

The original article can be found online at https://doi.org/10.1007/ s11249-020-01289-7.

Koki Kanda

koki.kanda.a5@tohoku.ac.jp

1 Laboratory of Tribology and Nanointerface Engineering, Department of Mechanical Systems Engineering, Tohoku University, Sendai, Japan

2 Sun Medical Technology Research Corporation, Suwa, Japan
Sun Medical Technology Research Corporation, Suwa, Japan.

2. The spelling of the "SiC-made seal rung" text in "Abstract" section was incorrect. It should read as SiC-made seal ring.

Publisher's Note Springer Nature remains neutral with regard to jurisdictional claims in published maps and institutional affiliations. 